Original Article

Artigo Original

Dionísia Aparecida Cusin Lamônica

Cora Sofia Takaya Paiva ${ }^{1}$

Dagma Venturini Marques Abramides ${ }^{1}$ Jamile Lozano Biazon²

Keywords

Cerebral Palsy

Child Language

Child Development

Child Preschool

Language Disorders

Communication

Descritores

Paralisia Cerebral

Linguagem Infantil

Desenvolvimento Infantil

Pré-escolar

Transtornos da Linguagem

Comunicação

Correspondence address:

Dionísia Aparecida Cusin Lamônica

Alameda Octávio Pinheiro Brisolla, 9-75,

Vila Universitária, Bauru (SP), Brasil,

CEP: 17012-901.

E-mail: dionelam@uol.com.br

Received: 11/26/2013

Accepted: 01/12/2015

\section{Communication skills in individuals with \\ spastic diplegia}

\author{
Habilidades comunicativas em indivíduos \\ com diplegia espástica
}

\begin{abstract}
Purpose: To assess communication skills in children with spastic diplegia. Methods: The study included 20 subjects, 10 preschool children with spastic diplegia and 10 typical matched according to gender, mental age, and socioeconomic status. Assessment procedures were the following: interviews with parents, Stanford - Binet method, Gross Motor Function Classification System, Observing the Communicative Behavior, Vocabulary Test by Peabody Picture, Denver Developmental Screening Test II, MacArthur Development Inventory on Communicative Skills. Statistical analysis was performed using the values of mean, median, minimum and maximum value, and using Student's $t$-test, Mann-Whitney test, and Paired $t$-test. Results: Individuals with spastic diplegia, when compared to their peers of the same mental age, presented no significant difference in relation to receptive and expressive vocabulary, fine motor skills, adaptive, personal-social, and language. The most affected area was the gross motor skills in individuals with spastic cerebral palsy. The participation in intervention procedures and the pairing of participants according to mental age may have approximated the performance between groups. Conclusion: There was no statistically significant difference in the comparison between groups, showing appropriate communication skills, although the experimental group has not behaved homogeneously.
\end{abstract}

\section{RESUMO}

Objetivo: Verificar habilidades comunicativas em crianças com diplegia espástica. Métodos: Participaram deste estudo 20 indivíduos, 10 crianças pré-escolares com diplegia espástica e 10 típicas, pareadas quanto ao gênero, idade mental e nível socioeconômico. Os procedimentos de avaliação foram: entrevista com os pais;Stanford-Binet; Gross Motor Function Classification System; Observação do Comportamento Comunicativo; Teste de Vocabulário por Imagem Peabody; Teste de Screening de Desenvolvimento Denver II; e Inventário de Desenvolvimento de Habilidades Comunicativas MacArthur. O tratamento estatístico foi realizado por meio dos valores de média, mediana, valor mínimo e valor máximo, e a utilização dos testes Teste $t$ de Student: Teste de Mann-Whitney e Teste $t$ Pareado. Resultados: Os indivíduos com diplegia espástica, quando comparados aos seus pares, de mesma idade mental, não apresentaram diferenças significativas em relação ao vocabulário expressivo e receptivo, habilidades motora fino-adaptativas, pessoal-social e linguagem. A área motora grossa foi a mais prejudicada nos indivíduos com paralisia cerebral do tipo diplegia espásticaem relação às crianças com desenvolvimento típico. A participação em procedimentos de intervenção e o pareamento dos participantes pela idade mental pode ter aproximado o desempenho entre os grupos.Conclusão: Não houve diferença estatisticamente significativa na comparação entre os grupos, demonstrando habilidades comunicativas adequadas, embora o grupo experimental não tenha se comportado de forma homogênea.

Study carried out at the School of Dentistry of Bauru, Universidade de São Paulo - USP - Bauru (SP), Brazil. (1) School of Dentistry of Bauru, Universidade de São Paulo - USP - Bauru (SP), Brazil.

(2) Clínica Albert Sabin - Bauru (SP), Brazil.

Conflict of interests: nothing to declare. 


\section{INTRODUCTION}

The dynamic nature involving the acquisition of language and the variability of interfering factors in this process brings about challenges to the understanding of this phenomenon, especially among children with brain injuries ${ }^{(1-5)}$.

The trajectory of child development is determined by complex interactions between biological, psychosocial and environmental factors ${ }^{(6)}$, and for the comprehension of this process it is necessary the knowledge of several interfering variables. These factors concern overall integrity of the nervous system, maturation process, sensory integrity, cognitive and intellectual abilities, processing of information or perceptive aspects, emotional factors and influence of the environment ${ }^{(7,8)}$.

The delays or the differences in language acquisition patterns may be sensible indicators of influences in overall development ${ }^{(9)}$, by multifactorial nature involving these learning processes.

The receptive vocabulary develops quickly during childhood and builds the bases for language acquisition and literacy ${ }^{(10)}$. Variations in the receptive vocabulary are associated to school performance, besides being a risk indicative factor for the overall development of the child ${ }^{(11,12)}$.

Some authors ${ }^{(13,14)}$ have shown that studies on the prevalence of communication disorders in individuals with cerebral palsy, including receptive and expressive abilities, are scarce. Other authors informed ${ }^{(13)}$ that there is an absence of studies which prospectively examine communication abilities, including the acquisition of pre-linguistic stages, in relation to motor function and comorbities.

The cerebral palsy of spastic diplegia type (CP-D) is characterized by bilateral compromise, involving the four limbs, especially the lower ones ${ }^{(15)}$, although it is necessary to know about the functional development that this conditions has on the child's performance ${ }^{(16-18)}$.

The severity of motor compromising, as well as the associated problems, such as: sensory, perceptive, cognitive, communication and behavior disorders, are different for each child with cerebral palsy, resulting in great variability of function in all domains ${ }^{(3)}$. Other risk factors involved in $\mathrm{CP}$, among which there is prematurity, low weight, socioeconomic status and environmental opportunities ${ }^{(19-22)}$.

The impact of $\mathrm{CP}$ in communicative abilities has received attention from the literature, reflecting the importance of communication for social and educational participation, aiming at the effectiveness of intervention programs which favor the full development of these individuals ${ }^{(17,18,23)}$.

Given the above, the objective of this study was to verify communicative abilities among children with spastic diplegia.

\section{METHODS}

This project was approved by the Ethics Committee on Research with Human Beings (Comitê de Ética em Pesquisa com Seres Humanos - CEP) of the Faculdade de Odontologia de
Bauru, Universidade de São Paulo (protocol number 096/2010). The legal representatives signed Informed Consent previously to the beginning of data collection.

Twenty individuals took part in this study, 10 of them with cerebral palsy of spastic diplegia type - Experimental Group (EG) —, who met the inclusion criteria, and 10 individuals with typical development - Control Group (CG). This research is a cross-sectional study.

Inclusion criteria of the EG: having been diagnosed with spastic diplegia CP; chronological age (CA) between 44 and 83 months; absence of sensorineural hearing loss; absence of visual alterations which would compromise the conduction of the procedure; having intelligence quotient (IQ) above 70 points; not having history of convulsion or epilepsy. The participants went through auditory and visual assessments previously to the procedures of the study.

Inclusion criteria of the CG: having typical development; being paired up with the EG as for gender, mental age (MA) and socioeconomic status.

All participants were submitted to psychological evaluation in order to establish mental age, so that the groups could be paired up. The instrument used was the new version of the Stanford-Binet method ${ }^{(24)}$ which provides a measure of MA, as well as the IQ, through the formula IQ $=\mathrm{MA} / \mathrm{CA} \div 100$. As a criterion for pairing, the MA between EG and CG should not exceed two months.

For the classification of the level of motor behavior function, the measures of the Gross Motor Function Classification System (GMFCS) were used ${ }^{(25)}$.The socioeconomic criterion Brazil $^{(26)}$ was used in order to characterize the sample. According to the instrument, $10 \%$ of them were from social class B2, $60 \%$ of them were $\mathrm{C} 1$ and $30 \%$ were $\mathrm{C} 2$.

Chart 1 shows the characterization of EG and CG in relation to gender, gestational age (GA) in months, chronological age in months, mental age, school education level (Maternal = MA; Kindergarten $=$ KG; Preschool $=$ PS; Elementary School $=$ ES; items I and II describe school graduation; NA = not attending school); intelligence quotient and level obtained in the GMFCS.

$90 \%$ of the EG are preterms. The gestational age varied from 22 to 35 weeks, (mean of 29.1), and the weight varied from 690 to $1,805 \mathrm{~g}$ (mean of $1,530 \mathrm{~g}$ ). From the CG, $90 \%$ were born at term, with gestational ages between 38 and 40 weeks (mean of 39.7) and weight between 3,200 and $4,180 \mathrm{~g}$ (mean of $3,457 \mathrm{~g}$ ). Chronological age of the EG varied from 44 to 83 months (mean of 63.7) and the CG varied from 33 to 83 months (mean of 58.6). The mental age varied from 34 to 83 for both groups (mean of $E G=60.3$ and $C G=60.7$ ), and the IQ varied between 77 and 106 for the EG (mean of 94.4) and between 101 and 106 (mean of 104.2) for the CG.

Despite all participants presenting IQ over 70, in the EG $40 \%$ of them presented MA below their CA, whilst in the CG this did not happen. All participants in the EG were under therapeutical monitoring in the areas of Physical Therapy, Speech Language and Audiology Therapy, Occupational and Psychological Therapy in a rehabilitation center. 
Chart 1. Characterization of the participants as for gender, gestational age (in weeks), weight at birth (in grams), chronological age (in months), menta age (in months), intelligence quotient, school education level obtained in the Gross Motor Function Classification System

\begin{tabular}{|c|c|c|c|c|c|c|c|c|c|c|c|c|c|c|}
\hline \multirow[t]{2}{*}{ Participants } & \multirow[t]{2}{*}{ Gender } & \multicolumn{2}{|c|}{$\begin{array}{c}\text { Gestational } \\
\text { age }\end{array}$} & \multicolumn{2}{|c|}{$\begin{array}{l}\text { Birth } \\
\text { weight }\end{array}$} & \multicolumn{2}{|c|}{$\begin{array}{c}\text { Chronological } \\
\text { age }\end{array}$} & \multicolumn{2}{|c|}{$\begin{array}{l}\text { Mental } \\
\text { age }\end{array}$} & \multicolumn{2}{|c|}{$\begin{array}{c}\text { Intelligence } \\
\text { quotient }\end{array}$} & \multicolumn{2}{|c|}{$\begin{array}{c}\text { School } \\
\text { education level }\end{array}$} & \multirow{2}{*}{$\frac{\text { GMFCS }}{\text { EG }}$} \\
\hline & & $E G$ & $C G$ & $E G$ & $\mathrm{CG}$ & $E G$ & CG & $E G$ & $C G$ & $E G$ & $C G$ & $E G$ & CG & \\
\hline 1 & $\mathrm{~F}$ & 32 & 40 & 1,535 & 3,300 & 44 & 33 & 34 & 34 & 77 & 103 & MA II & MA I & II \\
\hline 2 & M & 38 & 39 & 3,185 & 4,180 & 54 & 53 & 53 & 55 & 100 & 102 & KG II & KG I & II \\
\hline 3 & $\mathrm{~F}$ & 35 & 40 & 1,600 & 3,400 & 66 & 55 & 57 & 57 & 86 & 104 & PS II & KG I & II \\
\hline 4 & $F$ & 29 & 38 & 1,200 & 3,450 & 45 & 44 & 45 & 45 & 100 & 102 & NA & MA II & II \\
\hline 5 & $F$ & 25 & 40 & 1,700 & 3,200 & 66 & 55 & 57 & 57 & 86 & 104 & KG II & KG I & II \\
\hline 6 & $\mathrm{~F}$ & 29 & 29 & 1,100 & 1,350 & 83 & 83 & 83 & 83 & 100 & 102 & 2ndES & 2ndES & II \\
\hline 7 & $\mathrm{~F}$ & 32 & 40 & 1,920 & 3,200 & 53 & 55 & 56 & 57 & 106 & 104 & KG II & KG I & II \\
\hline 8 & M & 31 & 40 & 1,805 & 3,700 & 83 & 83 & 83 & 84 & 100 & 101 & 2ndES & 2ndES & III \\
\hline 9 & M & 27 & 41 & 0,690 & 3,290 & 70 & 68 & 70 & 72 & 100 & 106 & PS III & PS II & III \\
\hline 10 & $M$ & 22 & 40 & 1,120 & 3,400 & 73 & 56 & 65 & 64 & 89 & 114 & KG II & KGII & III \\
\hline
\end{tabular}

Caption: $\mathrm{EG}=$ experimental group; $\mathrm{CG}=$ control group; $\mathrm{MA}=$ Maternal; $\mathrm{KG}=$ kindergarten; $\mathrm{PS}=$ Preschool; $\mathrm{ES}=$ Elementary School; $\mathrm{NA}=$ not attending school; GMFCM = Gross Motor Function Classification System; F = Female; $M=$ Male

The following instruments were used:

- MacArthur Development Inventory on Communicative Skills (DDCM) $)^{(27)}$, applied with parents in order to verify the receptive and expressive vocabulary (part D). The data were analyzed according to the previewed rules in the guidelines of this inventory.

- Observing the Communicative Behavior $(\mathrm{OCB})^{(28)}$. The participants performed interactive activities, which were filmed for later analysis. The length of footage varied from 30 to 40 minutes. We analyzed answers from 26 communicative categories: Interaction; Communicative intention; Eye contact; Oral production; Production of words; Production of sentences; Respect to the shifts; Beginning of shift; Participation in dialogic activity; Narrative; Logical time sequence; Understanding of concrete situations; Understanding of abstract situations; Execution of simple orders; Execution of complex orders; Symbolic playing; Exploring of objects; Exploration of objects; Attention span; Interest for toys; Informing function; Protesting function; Requiring function; Offering function; Imitating function. The OCB was calculated according to the following criteria: $0=$ not presented; $1=$ presented in restricted situations; $2=$ presented in any situation. For the statistical treatment, it was performed a sumo $f$ the categories obtained after the analysis of the footage. Considering the total of items and the analysis criteria, the maximum sum reached the score of 52 points.

- Vocabulary Test by Peabody Picture (VTPP) ${ }^{(29)}$, applied with the objective of evaluating the receptive vocabulary. According to the rules proposed by the instruction manual of the test, in order to establish individual scoring, the floor and the ceiling were established, and the necessary calculation was made, in order to fulfill the following classification: low inferior (1), low superior (2), low middle (3), high middle (4), high inferior (5), high (6) and high superior (7).
- Denver Developmental Screening Test II (DDST-II) ${ }^{(30)}$. Evaluates the following skills: Personal-Social (PS), Language (LG), Fine-Adaptive Motor Skill (FAM) and Gross Motor Skill (GM). Its application was performed through direct testing, from the observation of behavior and the consideration of history reported by parents, and the analysis followed the proposed in the guidelines of the instrument.

In order to present the results regarding the used procedures, we used the mean, median, minimum and maximum values, and the Student's $t$ Test, the Mann-Whitney Test and the Paired $t$ Test.

\section{RESULTS}

Table 1 presents mean, median, minimum and maximum values, presented in percentage, and values of $t$ and $\mathrm{p}$ in the comparison between groups in OCB, DDCM and DDST-II, through the Student's $t$ Test.

In relation to the instruments OCB, DDCM (receptive and expressive vocabulary) and DDST-II, in language, personal-social and fine-adaptive motor skill areas, there was no difference in the comparison between groups. There was a statistically significant difference in the Gross motor skill area of the DDST-II in comparison between groups. It is noteworthy that in DDST-II, by mean, the CG had a better performance in all areas in comparison to the EG.

Table 2 presents mean, median, minimum and maximum values and p-value in comparison between the EG and CG, in the VTPP instrument, through the use of the Mann-Whitney test. The significance level used was $\mathrm{p} \leq 0.05$. There was no statistically significant difference in the comparison between groups. However, another analysis is possible. The range of occurrence of classification of the VTPP in the EG varied between 2 and 6, and for the CG between 4 and 7 , which reinforces that individuals with $\mathrm{CP}$ presented heterogeneity in the development of this skill. 
Table 1. Results from the observation of Communicative Behavior and Receptive and Expressive Vocabulary of the MacArthur Development Inventory on Communicative Skills and the Denver II Screening Test of Development in the comparison between the Experimental Group and the Control Group

\begin{tabular}{|c|c|c|c|c|c|c|}
\hline Instruments / Group & Mean & Median & Minimum & Maximum & $t$-value & $p$-value \\
\hline \multicolumn{7}{|l|}{ OCB } \\
\hline$E G$ & 48.6 & 51.0 & 31.0 & 52.0 & \multirow{2}{*}{-1.528} & \multirow{2}{*}{0.144} \\
\hline CG & 51.7 & 52.0 & 51.0 & 52.0 & & \\
\hline \multicolumn{7}{|l|}{ DDCM } \\
\hline \multicolumn{7}{|l|}{ Receptive vocabulary } \\
\hline$E G$ & 96.2 & 99.2 & 81.0 & 100.0 & \multirow{2}{*}{-1.707} & \multirow{2}{*}{0.105} \\
\hline CG & 99.4 & 99.5 & 98.7 & 100.0 & & \\
\hline \multicolumn{7}{|l|}{ Expressive vocabulary } \\
\hline$E G$ & 92.1 & 97.3 & 56.2 & 99.8 & \multirow{2}{*}{-1.079} & \multirow{2}{*}{0.295} \\
\hline CG & 96.9 & 98.9 & 90.2 & 99.8 & & \\
\hline \multicolumn{7}{|l|}{ DDST-II } \\
\hline \multicolumn{7}{|l|}{ Personal-social } \\
\hline$E G$ & 58.7 & 60.5 & 37.0 & 83.0 & \multirow[t]{2}{*}{-1.042} & \multirow[t]{2}{*}{0.311} \\
\hline $\mathrm{CG}$ & 65.2 & 61.0 & 54.0 & 83.0 & & \\
\hline \multicolumn{7}{|c|}{ Fine-adaptive motor skill } \\
\hline$E G$ & 64.6 & 60.5 & 44.0 & 83.0 & \multirow[t]{2}{*}{-0.277} & \multirow[t]{2}{*}{0.785} \\
\hline CG & 66.2 & 69.5 & 45.0 & 83.0 & & \\
\hline \multicolumn{7}{|l|}{ Language } \\
\hline$E G$ & 65.7 & 66.5 & 37.0 & 83.0 & \multirow[t]{2}{*}{0.187} & \multirow[t]{2}{*}{0.854} \\
\hline $\mathrm{CG}$ & 66.8 & 67.5 & 39.0 & 83.0 & & \\
\hline \multicolumn{7}{|l|}{ Gross motor skill } \\
\hline$E G$ & 38.0 & 38.0 & 24.0 & 55.0 & \multirow[t]{2}{*}{-7.902} & \multirow[t]{2}{*}{$0.000^{*}$} \\
\hline CG & 72.1 & 72.0 & 57.0 & 83.0 & & \\
\hline
\end{tabular}

*Significant values $(\mathrm{p} \leq 0.05)-$ Student's $t$ Test

Caption: $\mathrm{EG}$ = experimental group; $\mathrm{CG}=$ control group; $\mathrm{OCB}=$ Observing the communicative behavior; DDCM = MacArthur Development Inventory on Communicative Skills; DDST-II = Denver II Development Screening Test

Table 2. Results of the Vocabulary Test by Peabody Picture in the comparison between the experimental group and the control group

\begin{tabular}{lcccccc}
\hline VTPP & Group & Mean & Median & Minimum & Maximum & p-value \\
\hline Receptive & EG & 4.6 & 4.5 & 2.0 & 6.0 & \multirow{2}{*}{0.630} \\
vocabulary & CG & 5.6 & 6.0 & 4.0 & 7.0 & \\
\hline
\end{tabular}

Signifficant values $(\mathrm{p} \leq 0.05)$ - Mann-Whitney Test

Caption: EG = experimental group; CG = control group; VTPP = Vocabulary Test by Peabody Picture

Table 3.Result of the MacArthur Development Inventory on Communicative Skills Test in the comparison of the receptive and expressive vocabularies between the experimental group and the control group

\begin{tabular}{llcc}
\hline Group & DDCM & Mean (SD) & p-value \\
\hline \multirow{2}{*}{ EG } & Receptive vocabulary & $96.2(6.1)$ & \multirow{2}{*}{0.138} \\
& Expressive vocabulary & $92.1(13.9)$ & \\
\multirow{2}{*}{ CG } & Receptive vocabulary & $99.4(0.4)$ & \multirow{2}{*}{$0.020^{*}$} \\
& Expressive vocabulary & $96.9(2.7)$ & \\
\hline
\end{tabular}

*Signifficant values $(\mathrm{p} \leq 0.05$. $)$ - Paired t Test

Caption: $E G$ = experimental group; $C G$ = control group; DDCM = MacArthur Development Inventory on Communicative Skills; SD = standard deviation

Table 3 presents mean, standard deviation values and p-value in the comparison between groups as for the DDCM (receptive and expressive vocabularies) variables, through the use of the Pair $t$ Test. The level of significance adopted was $\mathrm{p} \leq 0.05$. There was no difference between the receptive and the expressive vocabulary for the EG, but there was for the CG.

\section{DISCUSSION}

In this study, prematurity and low weight (Chart 1) are relevant risk factors. The literature has presented the relation of these with brain insults, which can cause injuries compatible with $\mathrm{CP}$, and also associating it to determinant factors for the development of complex language functions ${ }^{(5,6,11,19,22)}$. The Periventricular Leukomalacia (PVL) is frequent in preterms, and it can also be found among newborn at term, when the insults occur until the third gestational trimester ${ }^{(20)}$.

The injuries resulting in CP-D represent ischemic damage of the periventricular zone, limited to dorsal and lateral tracts, along with the lateral ventricles ${ }^{(15-18)}$. They usually affects the motor fibers of the cortex and the association of visual, auditory and somesthesic functions, with the possibility of interferences in the processing of information ${ }^{(2)}$. There is a significant correlation between intensity and motor disorders and the extension of PVL. The fibers directed to the lower limbs are located in median positions, justifying the predominance of aggravations in the lower limbs ${ }^{(2,15,17,19,20)}$.

In this perspective, the neuropsychomotor development, despite the preview of alterations, offers better conditions for the acquisition of neck and trunk control, favoring the use of hands and the possibility of better manipulative and interactive skills. The CP-D is characterized by the heterogeneity of motor, cognitive and behavioral manifestations, with a difficulty of forming homogeneous groups, even for those individuals who received the same classification as for the topography of the 
origin of the brain injury and the affected members ${ }^{(7,15)}$. With this consideration, we used the terminology, based on the GMFCS classification $^{(25)}$ to address the functional motor performance, as verified in the literature ${ }^{(2,3,19,22)}$, confirming the prevalence of the classification degrees of the GMFCS in CP-D, compatible to the ones found in this study. A limitation of this study was the lack of use of results of imaging tests in order to verify the presence of PVL as a sequel of neurological insult. This occurred for some reasons. Some participants underwent cranial ultrasound, which is considered a golden-standard for this kind of diagnosis ${ }^{(20)}$; others underwent Magnetic Resonance Imaging (MRI) or Computed Tomography (CT) in different moments in life and in different diagnosis centers, with no standard for the exams, and few of them were available for the family.

As for the communicative development, individuals with CP are not a homogeneous group ${ }^{(1,3,7,9,12-14)}$. It noteworthy that it is not possible to draw a profile of their communicative abilities in general, considering only the diagnosis "cerebral palsy", once that the clinical conditions are complex, and the severity of the symptoms is substantially variable and it involves multifactorial conditions. For such, it is necessary to consider subgroups according to the brain injury, severity, classification as for the type, location of the motor alteration, degree of functional compromising, among others. In this study, we conducted a methodological control, trying to group individuals with CP-D who presented similar characteristics as for their motor conditions, mental age and socioeconomic status. We emphasize that the findings cannot be generalized, once the EG, despite the control of the variables, is too small as a populational sample. However, reflections are relevant.

Authors ${ }^{(13,14)}$ have shown that studies on the prevalence of communication disorders, including receptive and expressive abilities, are scarce. It is inferred that the participation in intervention procedures and the pairing by MA may have brought closer the performance between groups. It is noteworthy that, with this pairing, it was inferred that children in both groups could demonstrate similar conditions in receptive aspects.

In relation to OCB (Table 1), one of the skills which must be emphasized, as for performance, refers to the time of attention, which was less punctual in individuals with CP. Despite not being possible to visualize this data in the table, it must be stressed that difficulties of attention in individuals with CP-D are predictable ${ }^{(1,2,19)}$. The study ${ }^{(1)}$ showed that about 35 to $53 \%$ of individuals with $\mathrm{CP}$ have problems in executive functions, especially the ones related to attention spans. Delays in recognizing this difficulty may have a significant cumulative effect on the development of language, academic and social learning ${ }^{(1,2,12,19)}$.

When language development is approached in children, it is necessary to stress that the evaluation of receptive skills provides valuable information on the nature of the problem although there are Less indicators for the verification of delays, which can lead to difficulties in early detection, which may cause interferences in future performance ${ }^{(8)}$. However, the use of the only measure of a language component is enough to determine the severity of language impairment ${ }^{(5,8,23)}$.

In relation to the instrument DDCM, it is inferred that the difference found for the CG occurred because the family members of the child with typical development may have considered changes or phonological omissions such as difficulties to express themselves, even considering that those are expected at this age, for example, the acquisition of consonant groups. On the other hand, mothers of children with CP may have considered the possibility of communicating the concept, regardless the production-target Word being correct or not. Further studies must approach this aspect, considering the influence of the phonological aspect for the learning process. Authors ${ }^{(23)}$ have shown that the language competences may be underestimated among children with lighter motor alterations. The studies which point to differences between receptive and expressive vocabulary in CP usually consider the severity of the motor disorder and the influence of alterations in the shoulder girdle, the control of orofacial muscles and the pneumophonoarticulatory coordination, bringing about inferences into expressive abilities $^{(3,12)}$. The literature shows that the trend is that individuals with CP present better receptive skills rather than expressive ones, once that motor disorder interferes in the production of speech and, thus, expressive aspects may be jeopardized. This may be observed in studies comparing, for example, the development of individuals with diplegia and quadriplegia ${ }^{(12,16)}$.

In order to characterize language, involving receptive and expressive aspects, other variables must be controlled, such as the influence of motor, personal-social, cognitive and environmental skills ${ }^{(5,8,12)}$.

It must be considered that, as literature reminds us, children learn from their interactions with people, events and objects, and that the time of exposure to guided and interactive activities favor development and performance in communicative activities, as well as CP interferes in different development domains, such as mobility, self-care and social function, being able to bring about the detriment of learning processes ${ }^{(7,9,12-14)}$. Thus, early intervention processes, family guidance, as well as the active participation of the child in different social environments, are essential for the development of these skills.

In the STDD-II as for Gross motor skills (Table 1), the difference between groups was already expected by the characteristics of CP-D itself, such as balance, gait and muscle tone alterations. The evidences in this study evaluate the ability of children as for their static and dynamic balance, for example, using the support of only one foot, hopping, among others. These activities were especially difficult for the EG, for they demand global motor skills, influenced by the motor condition of CP-D, considering the execution criteria and the functional possibilities, already pointed out in the motor classification by the GMFCS ${ }^{(25)}$. This finding is compatible to the literature ${ }^{(9,12,16,19,22)}$. The motor function acts significantly in the performance of the child in face of their independence, having complex interactions between the remaining functions of development, which may interfere in the performance of actions with autonomy, influencing learning in general $^{(7-10)}$ and the relations the child establishes with the environment.

The personal-social skill may represent the autonomy of the child in the social environments they usually are in and it involves, for example, daily life activities, which represent a direct relation to the Gross motor skill, especially at this age range. 
A study showed that ${ }^{(1)}$ children with $\mathrm{CP}$ and cognitive performances in accordance to standard normative patterns may be in the need for assistance in domains involving social skills. Thus, there must be a special care so that the child has valid interlocutors and so that they build concrete personal relations with individuals from different age ranges, especially in school environment, in order that, despite their motor difficulties, the social environment favors their full development. They must present themselves as active subjects of the group in which they belong to, once the interactions and socialization are important not only for learning but also for the development of the personality (self-concepts, self-stem and social skills).

In the personal-social area we evaluated the personal reactions of the child in face of the social environment they experience regarding performance, with independence, in daily life tasks, involving the organization of stimuli, handling, social skills and the understanding of contexts. The children from the EG used to live in environments with stimuli in several development areas since a very early age and other social environments, such as regular school, that, in addition to the characteristics of this group being studies, in particular, the classification of the GMFCS, favor these findings.

Another matter refers to the performing o daily life activities independently. A study ${ }^{(2)}$ stated that therapeutic processes with family guidance and environmental acting tend to favor the development of social skills with autonomy. It must be pinpointed that in the DDST-II, specifically, this skills, is questioned as for the performing of daily life activities, such as eating by themselves, getting dressed, being able to brush their teeth, among others. Thus, the child received positive scoring is they performed the daily life activity, even if not perfectly.

As for the fine-adaptive behavior, the DDST-II, in this age range, verifies the abilities of the child as for organizations of stimuli, the performing of delicate traits, the manipulation of small objects, the use of fine skills in daily life activities, among others. Some considerations are important as for the obtaining of answers from individuals in the EG. In the DDST-II, it was requested that the child performed activities such as: copying a circle, a cross and a square; drawing people, etc. In this circumstance, the correct performing of the task when the child presented the expected concept is evaluated, but the quality of the task was not demanded, thus, for example, in the drawing a person test, if the child would use an appropriate number of body elements, according to what is expected from their age range, they would be approved in the task, even if the drawing did not have good execution quality (too much pressure on the paper, crooked or disproportionate traits). In this context, it is important that the child may perform activities independently, in order to develop their motor skills in a more elaborate and coordinated way, and that the environment encourages their active participation in performing tasks. This development in CP-D is usually due, considering the manual abilities, to the exposure to daily life situations, the performing of therapeutic processes and other experiences in social environments, even if for that some adaptations are necessary in order to improve their performance ${ }^{(19)}$.
In the area of language of the DDST-II, the evaluation is performed through multiple factors, for example, semantics, syntax, counting of elements, the answer to the functionality of objects, among other aspects. It is emphasized that the EG consisted of children without intellectual impairments. This would bring greater consequences to the development of this skill. A study ${ }^{(11)}$ showed that cognitive skills were statistically related to the understanding of language in individuals with brain injury.

The results obtained in VTPP show that the individuals with CP-D are not an homogeneous group. The VTPP has been used as evidence of non-verbal $\mathrm{IQ}^{(29)}$.

Individuals in the EG were paired according to their mental age and presented intelligence quotient in normative levels, but a little below the scores obtained by their peers. A study ${ }^{(4)}$ with individuals with CP-D without intellectual deficiency showed that, even with receptive vocabulary within the standard patterns, the basic non-verbal skills of daily life, necessary for the psychosocial development, may be affected. Thus, it is necessary to consider that the development of language involves several factors which should be analyzed for the understanding of the way the process is given. It is noteworthy, according to the literature $^{(11,12)}$, that variations in receptive vocabulary are associated to school performance, and low receptive vocabulary is a risk factor for the global development of the child.

One positive aspect of this study was the analysis of language skills, also considering other dimensions of the development which could favor it, such as Gross motor skill, fine motor skill, and personal-social skill. The literature $^{(8,9)}$ presents that language skills may be underestimated if not understood along with other dimensions of the development.

Communication is a progressive and continuous process. The child must develop a series of communicative skills which will follow or ground the onset of more evolved language forms.

Future studies must follow language development in a longitudinal way, leading to greater contributions of understanding of this theme. One must not forget that among individuals with CP-D we expect alterations in the perceptive processes which will certainly interfere in the development of communication and subsequently in school learning.

This way, this study brings reflections which may favor the understanding of the communicative development of individuals with CP-D.

\section{CONCLUSION}

The individuals with spastic diplegia, when compared to their peers, do not present statistically significant differences in relation to the expressive and receptive vocabularies, to their fine motor skills, personal-social and language skills, although the experimental group did not behave homogeneously.

\section{ACKNOWLEDGEMENTS}

We are thankful to Fundação de Amparo à Pesquisa do Estado de São Paulo (FAPESP) for the support granted for the conducting of this research, process No. 2010/12920-9. 
*DACL designed the research, contributed to the analysis of the data and the writing of the manuscript; CSTP contributed collecting the data from the participants of the research, with the analysis of the data and the writing of the manuscript; DVMA contributed to the psychological evaluation and writing of the manuscript; JLB applied the GMFMS instrument and contributed to the writing of the manuscript.

\section{REFERENCES}

1. Pirila S, van der Meere JJ, Rantanen K, Jokiuoma M, Erikssin K. Executive functions in youth with spastic cerebral palsy. J Child Neurol. 2011;26(7):817-21.

2. Bottcher L. Children with spastic cerebral palsy, their cognitive functioning, and social participation: a review. Child Neuropsychol. 2010;16(3):209-28.

3. Geytenbeek J. Prevalence of speech and communication disorders in children with CP. Dev Med Child Neurol. 2010;53(1):10-1.

4. Crespo-Eguiláz N, Narbona J. Habilidades neurocognitivas de niños con leucomalácia periventricular: resultados preliminares em 15 sujetos. Rev Neurol. 2004;38(1):80-4.

5. Van Noort-van der Spek IL, Franken Mc, Weisglas-Kuperus N. Language functions in preterm-born children: a systematic review and metaanalysis. Pediatrics. 2012:129(4):745-54.

6. Samra HA, Mcgrath JM, Wehbe M. An integrated review of developmental outcomes and late-preterm birth. J Obstet Gynecol Neonatal Nurs. 2011;40(4):399-411.

7. Lamônica DAC. Paralisia cerebral e habilidades comunicativas. In: Fernandes FDM, Mendes BCA, Navas ALPGP. Tratado de Fonoaudiologia. São Paulo: Roca. 2010. p.381-5.

8. Conti-Ramsden G, Durkin K. Language development and assessment in the preschool period. Neuropsychol Rev. 2012;22(4):384-401.

9. Walle EA, Campos JJ. Infant language development is related to the acquisition of walking. Dev Psychol. 2014;50(2):336-48.

10. Taylor CL, Christensen D, Lawrence D, Mitrou F, Zubrick SR. Risk factors for children's receptive vocabulary development from four to eight years in the longitudinal study of Australian children. Plos One. 2013;8(9):e73046.

11. Pavlisa Ji, Simlesa S, Ljubesi囚 M. Cognitive abilities and language comprehension in preschool children with perinatal brain lesion. Coll Antropol. 2011;35(Suppl1):31-8.

12. Sigurdardottir S, Vik T. Speech, expressive language, and verbal cognition of preschool children with cerebral palsy in Iceland. Dev Med Child Neurol. 2011;53(1):74-80.

13. Coleman A, Weir KA, Ware RS, Boyd RN. Relationship between communication skills and gross motor function in preschool-aged children with Cerebral Palsy. Arch Phys Med Rehabil. 2013;94(11):2210-7.

14. Norberg A. Miniscalco C, Lohmander A, Himmelmann K. Speech problems affect more than one in two children with cerebral palsy: Swedish population based study. Acta Paediatric. 2013;102(2):161-6.
15. Rosenbaum P, Paneth N, Leviton A, Goldistein M, Bax M, Damiano D, et al. A report: definition and classification of cerebral palsy April 2006. Dev Med Child Neurol Suppl. 2007;49(6):8-14.

16. Chen CL, Chen KH, Lin KC, Wu CY, Chen CY, Wong AM, et al. Factors associated with motor speech control in children with spastic cerebral palsy. Chang Gung Med J. 2010;33(4):415-23.

17. Pavlova MA, Krägeloh-Mann I. Limitations on the developing preterm brain: impact of periventricular white matter lesions on brain connectivity and cognition. Brain. 2013;136(4):998-1011.

18. Marret $\mathrm{S}$, Vanhulle $\mathrm{C}$, Laquerriere A. Pathophysiology of cerebral palsy. Hand Clin Neurol. 2013;111;169-76.

19. RozeE, van Braeckel KN, van der Veere CN, Maathuis CG, Martijn A, Bos AF. Functional outcome at school age of preterm infants with periventricular hemorrhagic infarction. Pediatrics. 2009;123(6):1493-500.

20. Al Tawil KI, El Mahdy HS, Al Rifai MT, Tamim HM, Ahmed IA, Saif Al AS.Risk factors for isolated periventricular leukomalacia. Pediatr Neurol. 2012;46(3):149-53.

21. Ballot DE, Potterton J, Chirwa T, Hilburn N, Cooper PA. Developmental outcome of very low birth weight infants in a developing country. BMC Pediatr. 2012;12:11.

22. Rha DW, Chang Wh, Kin J, Sim EG, Park ES. Comparing quantitative tractography metrics of motor and sensory pathways in children with periventricular leukomalacia and different levels of gross motor function. Neuroradiology. 2011;53(12):996-1002.

23. Hustad KC, Gorton K, Lee J. Classification of speech and language profiles in 4-year old children with cerebral palsy: a prospective preliminary study. J Speech Lang Hear Res. 2010;53(6):1496-513.

24. Terman LM, Merrill MA. Medida de la inteligencia. Madrid: EspasaCalpe; 1944.

25. Palisano R, Rosembaum P, Walter S, Russell D, Madeira E, Galuppi B. Development and reliability of a system to classify gross motor function in children with cerebral palsy. Dev Med Child Neurol. 1997;39(4):214-23.

26. Associação Brasileira de Empresas de Pesquisa (2012) [Internet]. Critério de classificação socioeconômica Brasil. [cited 2011 Jun 6]. Available from: www.abed.org.

27. Teixeira ERA. Adaptação dos Inventários MacArthur de Desenvolvimento Comunicativo (CDI's) para o português brasileiro. In: Anais do II Congresso Nacional da ABRALIN. Taciro - Produção de CDs Multimídia. Mimeo; 2000; 479-87.

28. Ferreira AT. Vocabulário receptivo e expressivo de crianças com síndrome de Down [dissertação Mestrado]. Bauru: Faculdade de Odontologia da Universidade de São Paulo; 2010.

29. Dunn LM, Padilla ER, Lugo DE. Test de vocabulário por Imágenes Peabody (Peabody Picture Vocabulary Test). Manual del examinador. Adaptação Hispanoamericana do American Guindance Service. Minessota: Publishers' Building, Circle Pines; 1986.

30. Frankenburg WK, Dodds J, Archer P, Bresnick B, Maschka P, Edelman N. Denver II Training Manual. Denver: Denver Developmental Materials; 1992. 